\title{
Hyperactivity and Learning Deficits in Transgenic Mice Bearing a Human Mutant Thyroid Hormone $\beta 1$ Receptor Gene
}

\author{
Michael P. McDonald, ${ }^{1,4}$ Rosemary Wong, ${ }^{2}$ Gregory Goldstein, ${ }^{1}$ \\ Bruce Weintraub, ${ }^{2}$ Sheue-yann Cheng, ${ }^{3}$ and Jacqueline N. Crawley ${ }^{1}$ \\ ${ }^{1}$ Section on Behavioral Neuropharmacology \\ Experimental Therapeutics Branch \\ National Institute of Mental Health (NIMH) \\ ${ }^{2}$ Molecular and Cellular Endocrinology Branch \\ National Institute of Diabetes and Digestive and Kidney Diseases (NIDDK) \\ ${ }^{3}$ Laboratory of Molecular Biology \\ National Cancer Institute (NCI) \\ National Institutes of Health $(\mathrm{NIH})$ \\ Bethesda, Maryland 20892 USA
}

\begin{abstract}
Resistance to thyroid hormone (RTH) is a human syndrome mapped to the thyroid receptor $\beta$ (TR $\beta)$ gene on chromosome 3, representing a mutation of the ligandbinding domain of the TRB gene. The syndrome is characterized by reduced tissue responsiveness to thyroid hormone and elevated serum levels of thyroid hormones. A common behavioral phenotype associated with RTH is attention deficit hyperactivity disorder (ADHD). To test the hypothesis that RTH produces attention deficits and/or hyperactivity, transgenic mice expressing a mutant TRB gene were generated. The present experiment tested RTH transgenic mice from the PV kindred on behavioral tasks relevant to the primary features of ADHD: hyperactivity, sustained attention (vigilance), learning, and impulsivity. Male transgenic mice showed elevated locomotor activity in an open field compared to male wild-type littermate controls. Both male and female transgenic mice exhibited impaired learning of an autoshaping task, compared to wild-type controls. On a vigilance task in an operant chamber, there were no
\end{abstract}

differences between transgenics and controls on the proportion of hits, response latency, or duration of stimulus tolerated. On an operant go/no-go task measuring sustained attention and impulsivity, there were no differences between controls and transgenics. These results indicate that transgenic mice bearing a mutant human TR $\beta$ gene demonstrate several behavioral characteristics of ADHD and may serve a valuable heuristic role in elucidating possible candidate genes in converging pathways for other causes of ADHD.

\section{Introduction}

Resistance to thyroid hormone (RTH) is a heritable human condition defined by normal or elevated levels of thyroid-stimulating hormone (TSH) in the presence of high levels of serum triiodothyronine (T3) and thyroxine (T4), and resistance of pituitary or peripheral tissues to the actions of thyroid hormone (Refetoff et al. 1967, 1983, 1993; Refetoff 1982). RTH is linked to mutations in exons 9 and 10 of the human thyroid bormone $\beta$ receptor gene (TR $\beta)$, which codes proteins in the T3binding domain of the $\beta 1$ subtype (TR $\beta 1)$ of the thyroid hormone receptor (Parilla et al. 1991; Usala et al. 1991; Mixson et al. 1992; Takeda et al. 1992). Although mechanisms vary across kindred, these mutations typically decrease binding affinity of the

${ }^{4}$ Corresponding author.

LEARNING \& MEMORY 5:289-301 @ 1998 by Cold Spring Harbor Laboratory Press ISSN1072-0502/98 \$5.00

$$
\begin{array}{lllllllllllllll}
L & E & A & R & N & I & N & G & \underset{\mathbf{2 8 9}}{\boldsymbol{Q}} & M & E & M & O & R & Y
\end{array}
$$


TR $\beta 1$ receptor for T3 (Parilla et al. 1991; Takeda et al. 1992; Cheng 1995).

The phenotypic expression of RTH varies widely, with the degree of affliction ranging from subclinical to incapacitating (Auchus and Fuqua 1994; Jameson 1994; Usala 1994). Depending on whether pituitary or peripheral tissues are more greatly affected, patients with RTH may display symptoms of hyperthyroidism or hypothyroidism (Weintraub et al. 1981). A common symptom of RTH is attention deficit with hyperactivity disorder (ADHD; Hauser et al. 1993; Brucker-Davis et al. 1995; Stein et al. 1995; Matochik et al. 1996). In two studies, $50 \%-70 \%$ of RTH patients met the diagnostic criteria for ADHD (Hauser et al. 1993; Brucker-Davis et al. 1995), with the incidence in males $\sim 50 \%$ higher than in females. This is striking compared to an incidence of ADHD of $2 \%-5 \%$ in the population as a whole (Barkley 1981; Zametkin and Rapoport 1987). Patients with ADHD exhibit hyperactivity, inattention, learning deficits, and impulsivity (Barkley 1981, 1982, 1997; Woodard and Lansdown 1988; Barkley et al. 1992; Stein et al. 1995). On tasks measuring sustained attention and impulsivity, e.g., the go/no-go or continuous performance tasks which require subjects to respond under a given set of conditions and to refrain from responding under different conditions, performance of ADHD subjects is characterized by slower reaction times and fewer hits (inattention) as well as more false alarms (impulsivity) (Zahn et al. 1980, 1991; Sergeant and Scholten 1983, 1985; O'Dougherty et al. 1984; Tarnowski et al. 1986; Woodard and Lansdown 1988; Casey et al. 1997).

Knockout mice lacking the TR $\beta$ gene exhibit elevated TSH and free and total T3 and T4, but normal behavior (Forrest et al. 1996). Transgenic mice bearing the human PV mutant TR $\beta$ gene have been developed recently (Wong et al. 1997). The PV mutant TR $\beta 1$ was derived from a patient with severe RTH characterized by short stature, low weight, impaired learning, and ADHD, but no hearing loss (Parilla et al. 1991; Mixson et al. 1992; Wong et al. 1997). RTH transgenic mice exhibit increased circulating levels of free and total $\mathrm{T} 4$ and inappropriately normal levels of TSH, weight loss, and impaired growth. The mice were not hyperactive but exhibited an attenuated response to methylphenidate, a dopaminergic agonist, on open field activity. Whereas these phenotypes are consistent with those seen in RTH patients, additional experiments are necessary to evaluate the potential to use the RTH transgenic mice as a model for inves- tigating the causal mechanisms of ADHD. In the present experiment, we tested PV RTH transgenic mice and their wild-type littermates on behavioral tasks designed to assess processes impaired in ADHD: activity, attention, learning, and impulsivity.

\section{Materials and Methods}

\section{SUBJECTS}

Mutant PV TR $\beta 1$ cDNA was constructed as described previously (Meier et al. 1992) and was subcloned into the HindIII site of the human $\beta$ actin construct (BAP.2; gift of S. Goff, Columbia University, New York, NY). The injection of the purified ClaI fragment and preparation of transgenic mice were done according to the procedures of Hogan and Lacy (1986). Founders on a CD-1 background were analyzed by HindIII restriction digestion of tail DNA to release the $1.4-\mathrm{kb}$ transgene, followed by Southern analysis as described previously (Wong et al. 1997). The ratio of endogenous to mutant TR $\beta 1$ was $~ 30: 1$ in both brain and white adipose tissue (Wong et al. 1997). Mice exhibited elevated free and total $\mathrm{T} 4$ and inappropriately normal TSH (Wong et al. 1997). RTH mutant mice appeared grossly normal in body structure and appearance of fur. Subjects used for behavioral testing were 22 experimentally naive mice, $10 \mathrm{RTH}$ transgenic ( 4 male, 6 female) and 12 wild-type littermate controls ( 5 male, 7 female), 20 weeks old at the start of behavioral testing. Mice were housed in tub cages in groups of two or three, separated by gender. On ad libitum food and water, there was no overall difference in the body weights between the transgenic and control mice, $F(1,18)=4.02, P=0.0602$. However, there was a significant difference between males and females, $F(1,18)=55.43, P<P<$ 0.0001 , and a significant genotype $\times$ gender interaction, $F(1,18)=5.57, \quad P<0.0298$. Specifically, male transgenic mice [mean \pm s.e.M. (g): $30.6 \pm 1.9]$ weighed significantly more than male wild types $(26.1 \pm 1.6), t(8)=2.84, P=0.0110$. There were no differences between female transgenic and wild-type mice (transgenics, $20.4 \pm 0.4$; wild types, $20.8 \pm 0.3$ ). At the start of operant training, mice were maintained at $\sim 85 \%$ of their freefeeding weight by postsession feedings. Water was freely available in their home cages. The vivarium was maintained on an artificial 12/12-hr light/dark cycle, with lights on at 6 a.m. All procedures were

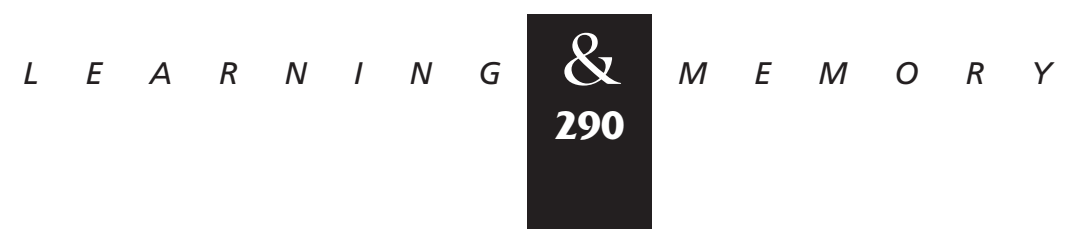


approved by the NIMH Animal Care and Use Committee, and followed the NIH Guidelines, "Using Animals in Intramural Research.'

\section{APPARATUS}

Exploratory locomotor activity was measured in an open field measuring $45 \times 45 \mathrm{~cm}$. The bottom of the open field was covered with a light layer of bedding material. A Digiscan analyzer [model RXYZCM(8) Omnitech Electronics, Columbus, $\mathrm{OH}]$ automatically recorded and analyzed the locomotor activity. The apparatus contained eight photocells in each horizontal direction $\sim 1 \mathrm{~cm}$ above the floor of the open field. An additional row of eight photocell beams was located $4 \mathrm{~cm}$ above one of the horizontal rows, to measure vertical activity.

Operant testing was conducted in two identical operant chambers (MED Associates, Lafayette, IN). Each chamber was equipped with two response levers on the front wall and a single response lever on the rear wall. Only one lever in each chamber was operational during the experimental sessions. A stimulus lamp was located $\sim 2$ $\mathrm{cm}$ above each of the three levers. A house light was located near the top of the rear wall to provide a source of low-level illumination. A recessed well was located on the front wall, $1 \mathrm{~cm}$ above the grid floor and an equal distance from each lever. Sweet food pellets weighing $20 \mathrm{mg}$ each (Formula P, P.J. Noyes Company, Lancets, $\mathrm{NH}$ ) were delivered through a tube to the food cup at appropriate intervals. The operant chambers were controlled by a DOS-based microcomputer running MED-PC software (MED Associates, Lafayette, IN). A sonalert was situated behind the front wall for the delivery of an 80-dB, 1900-Hz tone. The software controlled the contingencies and collected data from the experimental sessions.

\section{MEASURES OF MOTOR ACTIVITY AND COORDINATION \\ OPEN-FIELD ACTIVITY}

Each mouse was placed in the open field for 90 min. Scores were obtained at 5-min intervals and analyzed for horizontal and vertical activity. Because food restriction was required for the operant lever-press tasks, and food restriction may affect activity levels required for operant tasks (Challet et al. 1996), mice were retested in the open field after $24 \mathrm{hr}$ of food restriction. The open-field testing under food restriction was performed in an identical manner as the prerestriction open-field testing.

ROTOROD

The ability to maintain balance on a rotating cylinder was measured with a standard rotorod apparatus. The cylinder was $10.0 \mathrm{~cm}$ in diameter and was covered with a coarse black paper. Mice were confined to a section of the cylinder $22.0 \mathrm{~cm}$ long by Plexiglas dividers. Each mouse was placed on the cylinder, which was rotating at $6 \mathrm{rpm}$. Latency to fall off the rotating cylinder was measured. Mice that fell in less than 10 sec were given a second trial. Mice that did not fall during the 60-sec trial period were removed and given a score of $60 \mathrm{sec}$.

WIRE HANG

The ability to hang upside down from a wire screen was tested using a modified wire cover to a rat tub cage. The wire bars were $1 \mathrm{~mm}$ in diameter and spaced $1 \mathrm{~cm}$ apart. A rectangular area of the screen was taped off to confine the mice to a $10 \times 18 \mathrm{~cm}$ section of the screen. After mice were placed on the screen, it was waved gently in the air three times to force them to grip the wires. The screen was then immediately turned upside down, $70 \mathrm{~cm}$ above a large rodent housing cage, and latency to fall into the tub cage was measured. Mice that fell in less than $10 \mathrm{sec}$ were given a second trial. Mice that did not fall during the 60-sec trial period were removed and given a score of $60 \mathrm{sec}$.

\section{OPERANT TESTING}

There were three distinct phases of operant testing: autoshaping, simple reaction time, and go/ no-go tasks. Operant sessions were typically conducted 5 days per week.

AUTOSHAPING

In the first phase of operant testing, animals learned to press a lever under computer-controlled contingencies. Each session started with the illumination of the house light, which remained lit for the duration of the session. At the beginning of each trial, a cue lamp was illuminated. Pressing the lever below the cue lamp resulted in the immediate delivery of a reinforcer (food pellet) and extinguished the cue lamp. If the lever was not pressed after $8 \mathrm{sec}$, the cue lamp was extinguished and a food pellet was delivered simultaneously. For half the mice, the active lever was always the left lever

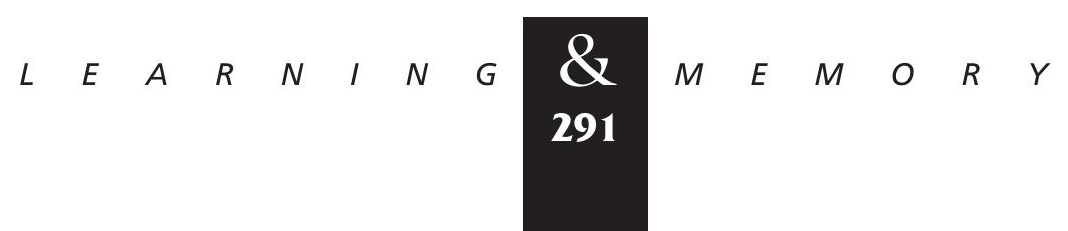


on the front wall; for the other half the active lever was always the right lever on the front wall. The goal of training was to teach the mice to press the lever to receive a food pellet before the $8 \mathrm{sec}$ had elapsed (i.e., while the cue lamp was illuminated). Lever presses while the cue lamp was extinguished carried no scheduled consequences. Environmental contingencies were controlled by an autoshaping computer program. Each session consisted of 40 trials, with an intertrial interval ranging from 15 sec to 3 min (mean $45 \mathrm{sec}$ ). Training sessions were conducted 5 days per week until all subjects met a criterion of earning 10 or more reinforcers during a single session. A reinforcer was defined as a food pellet earned by pressing the lever while the cue lamp was illuminated. The primary dependent measure was reinforcers earned per session, taken as an index of learning to press the lever for food.

SIMPLE REACTION TIME

After mice met the criterion (10 reinforcers/ session) on the autoshaping program, reactiontime training commenced using a procedure modified from McGaughy and Sarter (1995a). The reaction-time task measures latency to respond to the target stimulus, and is used commonly to assess attention in humans (Zahn et al. 1980, 1991; Pang et al. 1992; Douglas and Perry 1994) and animals (Dudchenko et al. 1992; Muir et al. 1992; Pang et al. 1992, 1993; Steckler and Sahgal 1995). Each trial began with a foreperiod ranging from 9 to $24 \mathrm{sec}$ in 3-sec increments (mean $15 \mathrm{sec}$ ), randomized across trials. At the end of the foreperiod the cue lamp was illuminated for $3 \mathrm{sec}$. A response during the 3-sec illumination period was classified as a hit and resulted in the delivery of a reinforcer and extinguishing of the cue lamp. After reinforcer delivery, the house light remained lit for $3 \mathrm{sec}$ to allow the subject to see and consume the food pellet, after which time the house light was extinguished and the 10-sec intertrial interval (ITI) was initiated. If the mouse failed to press the lever during the 3-sec stimulus duration, no food pellet was delivered and the cue lamp and house light were extinguished immediately. Such a trial was classified as a miss. The cue lamp and house light remained unlit for the duration of the ITI. Each daily session consisted of 40 trials or $40 \mathrm{~min}$, whichever came first, with the constraint that a trial in progress after $40 \mathrm{~min}$ had elapsed was allowed to finish before the termination of the session. A response during the foreperiod reset the foreperiod, so that an animal was required to refrain from responding for the entire duration of the foreperiod before the cue lamp was illuminated. No discrete environmental cue signaled the resetting of the foreperiod. Responses made during the last $3 \mathrm{sec}$ of the foreperiod were classified as prestimulus resets. Environmental events in the operant chambers were identical for prestimulus resets as for other resets, but prestimulus resets were treated differently in the data analysis (see below). Sessions were conducted using a 3-sec stimulus duration until subjects reached a criterion whereby a hit occurred on at least $80 \%$ of the trials and a prestimulus reset occurred on not more than $25 \%$ of the trials. Upon reaching this criterion, the stimulus duration was shortened progressively to $0.25 \mathrm{sec}$. An animal was required to meet the performance criterion of $\geqslant 80 \%$ hits and $\leqslant 25 \%$ prestimulus resets to move to the next level.

Upon reaching a stimulus duration at which asymptotic performance was below criterion level, the stimulus duration was changed to $3 \mathrm{sec}$ and allowed to restabilize. On all trials regardless of stimulus duration, subjects had $3 \mathrm{sec}$ during which to earn a reinforcer, beginning with stimulus onset. For trials on which the stimulus duration was shorter than $3 \mathrm{sec}$, the lever remained active after stimulus offset for the amount of time needed to make a 3-sec interval. Principal measures of interest were response latency, hits (percentage of trials on which a reinforcer was earned), and prestimulus resets (percentage of trials on which a prestimulus reset occurred). Other measures examined include number of prestimulus resets per trial, number of trials completed, session duration, postmiss burst rate (rate of responding during the $3 \mathrm{sec}$ of ITI immediately following a miss), and leverpress rates during the ITI and foreperiod.

\section{GO/NO-GO TASK}

The go/no-go task is a variation of the signaldetection paradigm that is used commonly to assesses both sustained attention (vigilance) and impulsivity in humans (Zahn et al. 1980, 1991) and animals (McGaughy and Sarter 1995a,b; McGaughy et al. 1996, 1997). After performance was restabilized on the simple reaction-time task with a 3-sec stimulus duration, the go/no-go contingencies were introduced. On the go/no-go version of the task, half of the trials were identical to those in the simple reaction time task with a 3-sec stimulus duration. These trials comprised the go condition.

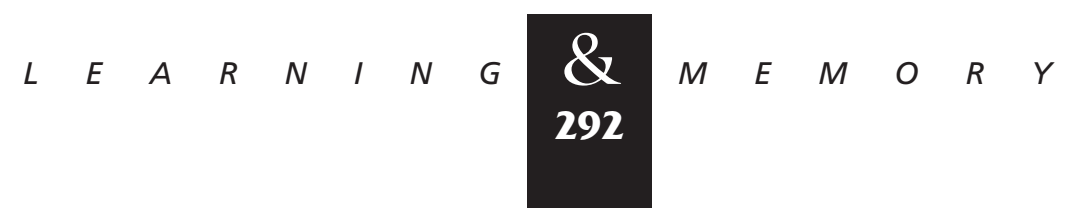


The other half of the trials comprised the no-go condition. The no-go trials were identical to the go trials with two exceptions. First, an 80-dB tone was initiated coincident with cue lamp onset on the no-go trials. Both stimuli terminated after 3 sec. Second, a reinforcer was earned by refraining from responding during the compound stimulus duration. Any response during the light/tone combination resulted in no reinforcer and the immediate extinguishing of the cue and house lamps and termination of the tone. As on the go trials, the house light remained illuminated for 3 sec following reinforcer delivery on the no-go trials to allow the mouse to find and eat the food pellet. In addition to the variables examined in the simple reaction time task, a signal detection analysis was used to analyze responding on the go/no-go task. Signal detection measures included probability of a hit [ $p$ (hit); percentage of trials in which the lever was pressed in the presence of the light only] and probability of a false alarm $[p(\mathrm{FA})$; percentage of trials on which the lever was pressed in the presence of the light/ tone compound]. In addition, sensitivity (SI) and response-bias (RI) indices were used as nonparametric analogs to the signal-detection parameters of discrimination and bias (Grier 1971; McGaughy and Sarter 1995a), using the following formulas: SI = $[p($ hit $)-\mathrm{p}(\mathrm{FA})] /[2 *(p$ (hit $)+\mathrm{p}(\mathrm{FA}))]-[p(\text { hit })+p(\mathrm{FA})]^{2}$ and $\mathrm{RI}=[p($ hit $)+p(\mathrm{FA})-1] /\left[1-(p(\text { hit })-p(\mathrm{FA}))^{2}\right]$.

\section{STATISTICAL ANALYSIS}

Group comparisons were conducted using analysis of variance (ANOVA). Within-subject comparisons were made using two- and three-factor repeated measures ANOVAs. Planned follow-up comparisons and post-hoc analyses were made using repeated-measures ANOVAs and Bonferronicorrected $t$-tests. All hypothesis testing was twotailed.

\section{Results}

\section{OPEN-FIELD ACTIVITY}

Male RTH transgenic mice were significantly more active than male wild types (Fig. 1). Repeated-measures ANOVA for horizontal activity showed a significant decrease in activity for all mice over the course of the 90-min session, $F(17,306)=51.78, \quad P<0.0001, \quad$ indicating that animals habituated over time. There was a significant main effect for genotype, $F(1,18)=5.23$, $P=0.035$. There was no main effect for gender, $\quad F(1,18)=2.06, \quad P=0.168$ but a significant genotype $\times$ gender interaction, $F(1,18)=5.17$, $P=0.036$. Post-hoc analysis of the genotype $\times$ gender interaction indicated that male transgenic mice were significantly more active than the male wildtype controls, $t(7)=3.62, P=0.009$. Female transgenic mice were not significantly different than the female wild-type controls, $t(11)=0.01, P=0.993$.

There was a significant decrease in vertical activity for all mice with repeated measurement, $\quad F(17,306)=8.06, \quad P<0.0001, \quad$ indicating that rearing behavior habituated over time (Fig.1). There was no significant main effect for genotype, $F(1,18)=2.12, P=0.163$, or gender, $F(1,18)=0.12, P=0.739$, but there was a significant genotype $\times$ gender interaction, $F(1,18)=6.24$,
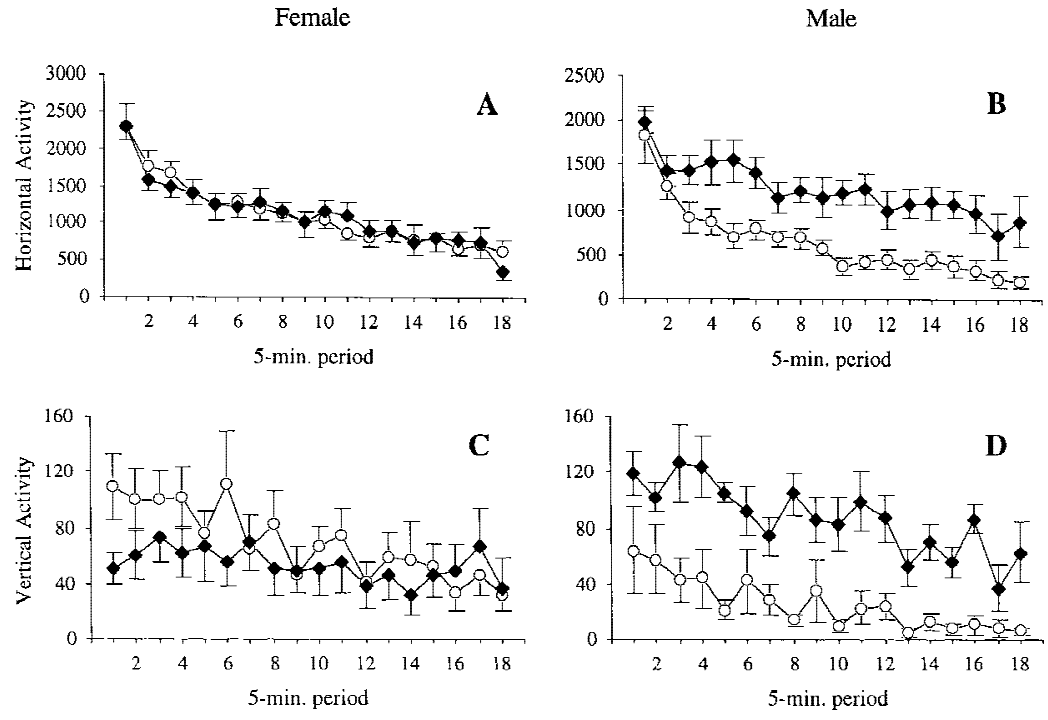

Figure 1: Open-field activity in RTH transgenic mice $(n=6$ female; $n=4$ male; ) and wild-type littermate controls ( $n=7$ female; $n=5$ male; $\bigcirc$ ). Horizontal and vertical beam breaks were tallied every $5 \mathrm{~min}$ for $90 \mathrm{~min}$. (A) Horizontal activity of female mice; $(B)$ horizontal activity of male mice; $(C)$ vertical activity of female mice; $(D)$ vertical activity of male mice. Male transgenic mice were significantly more active than male controls, on both horizontal and vertical activity. Data are presented as mean \pm S.E.M.

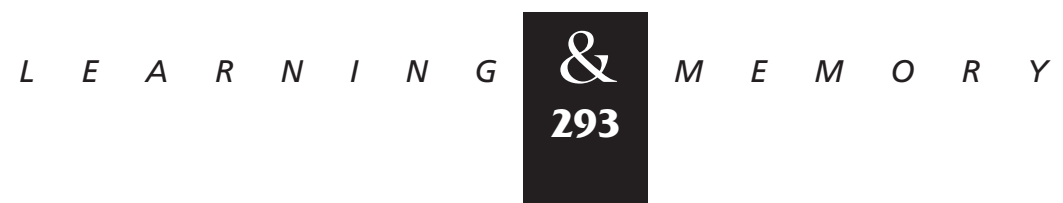




\section{McDonald et al.}

$P=0.022$. Post-hoc analyses of the genotype $\times$ gender interaction indicated that male RTH transgenic mice reared significantly more than the male wildtype controls, $t(7)=4.42, P=0.003$. Female transgenic mice were not significantly more active than the female wild-type controls, $t(11)=0.68$, $P=0.508$.

\section{ROTOROD/WIRE HANG}

There was no significant difference in rotorod performance between the two groups of mice $[F(1,20)=2.53, P=0.127]$. On the wire-hang task, none of the mice of either genotype fell off the wire screen; thus all mice received the maximal score of $60 \mathrm{sec}$.

\section{AUTOSHAPING}

All the mice reached the performance criterion on the autoshaping task by the 15 th session (Fig. 2). Repeated-measures ANOVA revealed a significant effect for number of reinforcers earned over 15 sessions, indicating that overall performance of all mice improved during the course of training, $F(14,280)=41.53, P<0.0001$. There were no overall significant differences between genotype, $F(1,18)=4.04, \quad P=0.060$, or gender, $F(1,18)=1.47, P=0.241$, and no significant genotype $\times$ gender interaction, $F(1$, $18)=0.57, P=0.458$. However, there was a significant session $\times$ genotype interaction, $F(14,280)=2.24$, $P=0.0069$, indicating that the RTH transgenic mice were significantly slower to learn to press the lever for

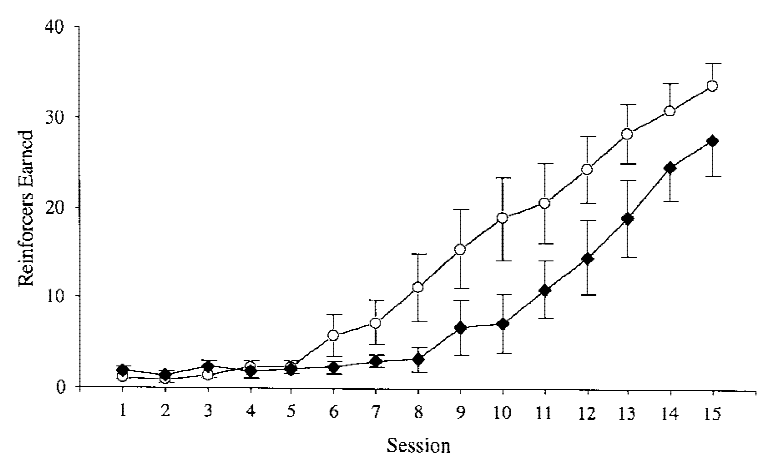

Figure 2: Reinforcers earned on a lever-press autoshaping task for RTH transgenic $(n=10 ; \bullet)$ and wildtype $(n=12 ; \bigcirc)$ mice. Subjects received 40 trials per day on the autoshaping program, for 15 days. Transgenic mice learned the lever-press task significantly slower than wild-type controls. Data are presented as mean \pm S.E.M. food compared to the wild-type mice (Fig. 2). Interactions for session $\times$ gender, $F(14,280)=0.74, P=0.739$, and session $\times$ genotype $\times$ gender, $\quad F(14,280)=0.53$, $P=0.650$, were not significant, indicating that the learning impairment was observed in both male and female transgenic mice.

\section{SIMPLE REACTION TIME}

After 34 sessions, all mice were performing at an asymptotic level at the 3-sec stimulus duration. The data from the last three sessions of asymptotic performance were averaged to provide a single score per measure per subject. At asymptote, there were no differences on any of the performance measures between the two genotypes (Table 1). Of 22 two subjects, 18 (8 transgenic and 10 controls) reached criterion-level performance at the 3-sec stimulus duration, and stimulus durations were reduced progressively for those subjects. The stimulus durations were reduced progressively until asymptotic performance was no longer at criterion level. The last stimulus duration at which criterion-level performance was achieved was considered the shortest stimulus tolerated. There was no difference in the shortest stimulus tolerated between transgenics $(1.19 \pm 0.40)$ and wild types $(1.25 \pm 0.35), F(1,18)=0.01, P=0.908$.

\section{GO/NO-GO}

Mice completed 12 sessions on the go/no-go task. The data from the last three sessions of asymptotic performance were averaged to provide a single score per measure per subject. There were no differences on any of the performance measures between the two genotypes (Table 2). Response latencies were significantly shorter for false alarms than for hits among both groups, $t(20)=6.22$, $P<0.0001$, suggesting that tone on the no-go trials was responsible for evoking more rapid responses than on trials presenting only a light stimulus. Introduction of the no-go contingencies did not immediately disturb performance on the go trials in either genotype (Fig. 3). However, by the 12th go/ no-go session $p$ (hit) was significantly lower than during the three go sessions immediately preceding introduction of the no-go trials, $t(20)=3.15$, $P=0.006$.

\section{OPEN-FIELD ACTIVITY IN FOOD-RESTRICTED MICE}

Because food restriction can affect exploratory activity in rodents (Challet et al. 1996) and food

$$
\begin{array}{llllllllllllllll} 
& E & A & R & N & I & N & G & \boldsymbol{Q} \\
\mathbf{2 9 4} & M & E & M & O & R & Y
\end{array}
$$


Table 1: Performance measures on the simple reaction time task

\begin{tabular}{lrrrr}
\hline Measure & \multicolumn{1}{c}{ Wild type } & RTH transgenic & $F$ & $P$ \\
\hline Trials completed & $37.58 \pm 2.39$ & $39.76 \pm 0.24$ & 0.52 & 0.482 \\
Session duration & $30.24 \pm 1.57$ & $29.89 \pm 1.43$ & 0.02 & 0.879 \\
$p$ (hit) & $0.77 \pm 0.04$ & $0.84 \pm 0.06$ & 1.01 & 0.331 \\
$p$ (prestimulus reset) & $0.14 \pm 0.03$ & $0.12 \pm 0.06$ & 0.31 & 0.583 \\
Resets per trial & $2.19 \pm 0.69$ & $1.65 \pm 0.38$ & 0.22 & 0.644 \\
Prestimulus reset trials (\%) & $14.63 \pm 3.33$ & $12.14 \pm 1.68$ & 0.32 & 0.581 \\
Response latency (hit) & $1.28 \pm 0.05$ & $1.24 \pm 0.07$ & 0.31 & 0.586 \\
ITI response rate & $0.98 \pm 0.25$ & $1.19 \pm 0.36$ & 0.24 & 0.645 \\
Burst rate (miss) & $14.50 \pm 2.75$ & $14.28 \pm 2.79$ & 0.00 & 0.958 \\
\hline
\end{tabular}

restriction was required for the operant tasks, open-field activity was retested in food-restricted mice to ensure that unusual activity levels did not affect performance in the operant chambers. After $24 \mathrm{hr}$ of food restriction, there was a significant decrease in horizontal activity over the 90-min session for all mice, $F(17,306)=17.08$, $P<0.0001$, indicating that animals habituated over time in a normal manner. There was no main effect for genotype, $F(1,18)=1.86, P=0.190$, or gender, $F(1,18)=0.15, \quad P=0.708$, and no genotype $\times$ gender interaction, $F(1,18)=0.56$, $P=0.464$. There were significant horizontal activity $\times$ gender $, \quad F(17,306)=3.07, \quad P<0.0001$, and horizontal activity $\times$ genotype $\times$ gender interactions, $F(17,306)=2.98, P<0.0001$. The horizontal activity $\times$ genotype interaction was not significant, $F(17,306)=1.60, P=0.063$. Post-hoc analysis of the horizontal activity $\times$ genotype $\times$ gender in- teraction indicated that male RTH transgenic mice habituated significantly more quickly than the male wild-type controls, $F(17,119)=2.28, \quad P=0.005$. Analysis of the horizontal activity of male mice by genotype showed that the male transgenic mice exhibited significantly reduced activity under food restriction, compared to free-feeding activity levels, $F(1,3)=12.38, P=0.039$. Differences between ad lib feeding and food-restricted activity levels in wild-type mice were not significant, $F(1,4)=1.03$, $P=0.368$. Female transgenic mice habituated more slowly than the female wild-type controls, $F(17,187)=1.82, P=0.028$ (Fig. 4).

On vertical activity after food restriction, there was a significant decrease in activity with repeated measurement, $F(17,306)=5.06, P<0.0001$, indicating that rearing behavior habituated over time (Fig. 4). There was a significant main effect for genotype, $F(1,18)=6.46, P=0.021$, and a signifi-

Table 2: Performance measures on the go/no-go task

\begin{tabular}{lrrrc}
\hline Measure & \multicolumn{1}{c}{ Wild type } & RTH transgenic & $F$ & $P$ \\
\hline Trials completed & $36.82 \pm 2.11$ & $29.81 \pm 4.88$ & 2.25 & 0.153 \\
Session duration & $31.46 \pm 2.18$ & $33.54 \pm 3.29$ & 0.31 & 0.588 \\
$p$ (hit) & $0.64 \pm 0.07$ & $0.57 \pm 0.13$ & 0.24 & 0.631 \\
$p$ (FA) & $0.24 \pm 0.05$ & $0.31 \pm 0.14$ & 0.33 & 0.575 \\
Response latency (hit) & $1.33 \pm 0.06$ & $1.30 \pm 0.11$ & 0.06 & 0.817 \\
Response latency (FA) & $0.93 \pm 0.08$ & $0.80 \pm 0.15$ & 0.67 & 0.426 \\
ITI response rate & $1.92 \pm 0.47$ & $2.93 \pm 1.20$ & 0.82 & 0.379 \\
Resets per trial & $3.64 \pm 0.68$ & $5.66 \pm 1.64$ & 1.72 & 0.209 \\
Prestimulus reset trials (\%) & $21.64 \pm 4.48$ & $25.67 \pm 8.31$ & 0.22 & 0.647 \\
Burst rate (miss) & $9.71 \pm 1.38$ & $6.16 \pm 1.46$ & 2.90 & 0.108 \\
Burst rate (FA) & $4.50 \pm 0.97$ & $4.84 \pm 1.55$ & 0.04 & 0.848 \\
Response index & $-0.11 \pm 0.22$ & $-0.16 \pm 0.24$ & 0.04 & 0.837 \\
Sensitivity index & $0.49 \pm 0.07$ & $0.39 \pm 0.12$ & 0.53 & 0.476 \\
\hline
\end{tabular}




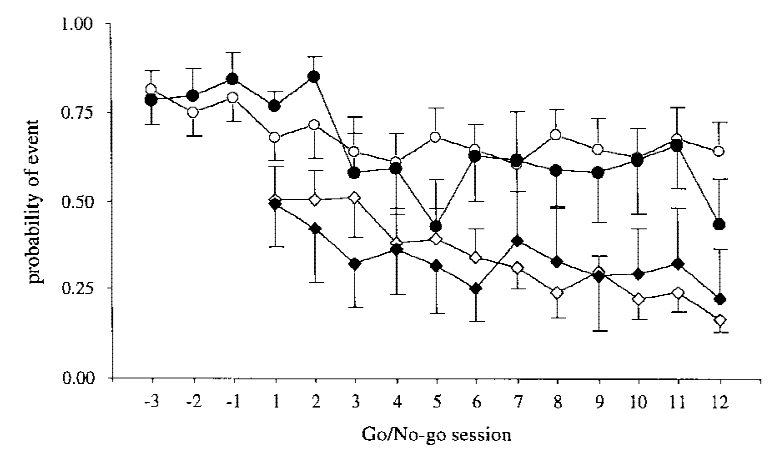

Figure 3: Probability of event for RTH transgenic $[n=10 ;(\bullet)$ hit; $(\diamond)$ FA] and wild-type $[n=12(0)$ hit; $(\diamond) \mathrm{FA}]$ mice on the reaction-time (sessions -3 to -1 ) and go/no-go (sessions 1-12) tasks. There were no differences between groups on probability of a hit [ $p$ (hit)] (circles) or probability of a false alarm $[p(\mathrm{FA})]$ (diamonds). Data are presented as mean \pm S.E.M.

cant genotype $\times$ gender interaction, $F(1,18)=5.46$, $P=0.031$. The main effect for gender was not significant, $F(1,18)=0.60, P=0.450$. There were significant vertical activity $\times$ genotype, $F(17,306)=2.98$, $P<0.0001$, and vertical activity $\times$ genotype $\times$ gender interactions, $F(17,306)=2.24, P=0.004$. The vertical activity $\times$ gender interaction was not significant, $F(17,306)=1.36, P=0.155$. Post-hoc analyses indicated that male RTH transgenic mice reared significantly less than the male wild-type controls overall, $t(7)=2.84, P=0.025$, and habituated more quickly during the 90-min session $F(17,119)=3.19$, $P<0.0001$. Female transgenic mice were not significantly different than the female wild-type controls, $t(11)=0.68, P=0.508$.

\section{Discussion}

Male RTH transgenic mice exhibited significant hyperactivity on measures of both horizontal and vertical spontaneous exploratory activity. Open-field activity of female transgenic mice was not different from that of female wild-type controls, for either horizontal or vertical movements. This gender difference in activity is similar to expression of ADHD in human patients, in whom the phenotype is more prevalent among males than females (Trites et al. 1979; Berry et al. 1985). The present results are also consistent with other rodent models of ADHD that report hyperactivity. For example, the spontaneously hypertensive rat (SHR; Knardahl and Sagvolden 1979; Sagvolden et al. 1993), neonatal rats injected with 6-hydroxydopamine (6-OHDA; Luthman et al. 1989), and the synaptosomal-associated protein-25 kD mutant mouse (Hess et al. 1992) all exhibit hyperactivity, although in some the increase in activity may be confounded by head bobbing, cerebellar ataxia, or hyperactivity consisting of repetitive rotations. In the present experiment, the types of behavioral activity exhibited by the transgenic mice were normal, and hyperactivity was not attributable to any unusual locomotor patterns or peculiarities.

After $24 \mathrm{hr}$ of food restriction, male RTH transgenic mice were significantly less active than male controls. The unusual pattern of changes after food restriction bears some resemblance to the paradoxical response of ADHD patients to dopaminergic agonists such as methylphenidate. Under normal circumstances ADHD patients are
Figure 4: Open-field activity in RTH transgenic mice $[(\diamond) n=6$ female; $n=4$ male] and wild-type controls $[(\bigcirc) n=7$ female; $n=5$ male] after $24 \mathrm{hr}$ of food restriction. Horizontal and vertical beam breaks were tallied every $5 \mathrm{~min}$ for 90 min. (A) Horizontal activity of female mice; $(B)$ horizontal activity of male mice; (C) vertical activity of female mice; $(D)$ vertical activity of male mice. After the first $10 \mathrm{~min}$, food-restricted male transgenic mice were significantly less active than male controls, on both horizontal and vertical activity. Data are presented as mean \pm S.E.M.
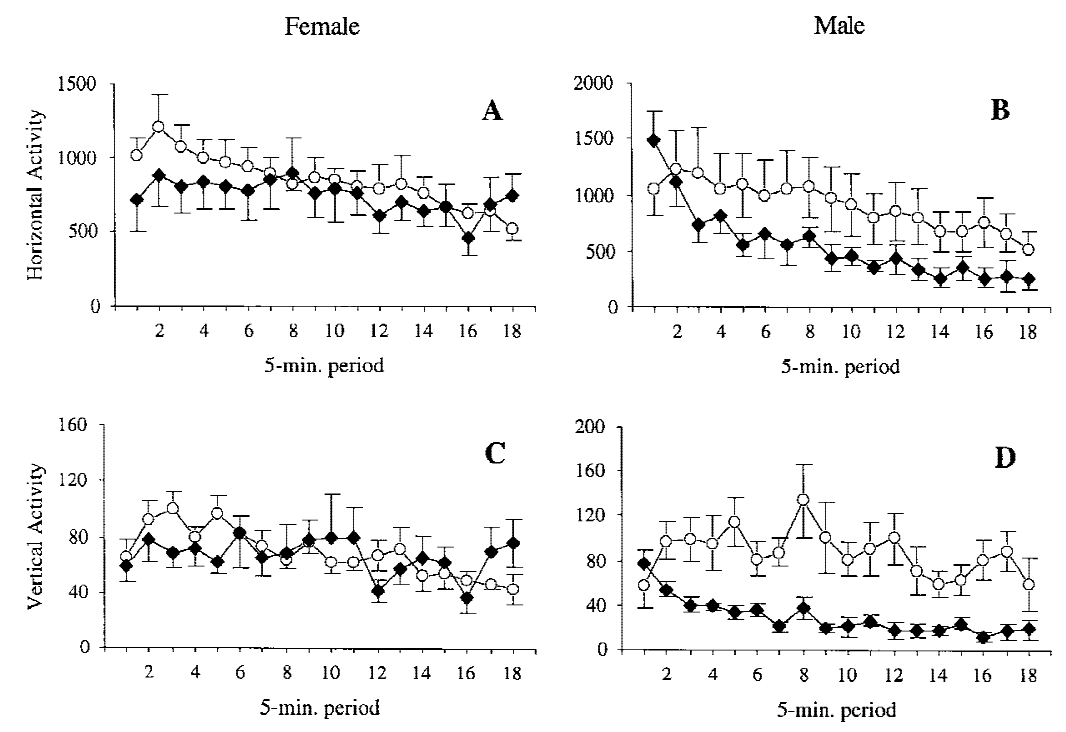

$$
\begin{array}{llllllllllllllll}
L & E & A & R & N & I & N & G & \underset{2}{\mathbf{2}} & \mathbf{Z} & M & E & M & O & R & Y
\end{array}
$$


hyperactive; however, when treated with catecholaminergic agonists, they exhibit reduced activity levels. The same treatment with catecholaminergic agonists in normal humans results in increased activity levels. RTH transgenic mice in a previous study were found to have an attenuated response to methylphenidate, compared to wildtype controls (Wong et al. 1997). The postrestriction hypoactivity of the male transgenic mice in the present experiment was not attributable to sensorimotor deficits, as they exhibited greater activity than controls in the first $5 \mathrm{~min}$, and equivalent activity during the second $5 \mathrm{~min}$. A significant gender $\times$ genotype $\times$ horizontal activity interaction indicates that the male transgenics started the open-field session significantly hyperactive compared to controls, and were significantly hypoactive by the end of the session. Whether the analogous activity patterns observed after food restriction are because of changes in the dopaminergic system in RTH transgenic mice is not known. Further exploration of these issues in RTH transgenic mice may be of interest both for understanding the neurochemistry of ADHD and for potential treatments of the condition.

RTH transgenic mice, both males and females, exhibited slower acquisition of a lever-press task (Fig. 2). This learning deficit exhibited by the transgenic mice is analogous to moderate learning deficits widely reported in ADHD patients (Barkley 1982; Woodard and Lansdown 1988; Stein et al. 1995). The fact that both male and female transgenic mice were impaired is consistent with reports showing that both male and female ADHD patients are learning impaired (Breen 1989; Horn et al. 1989; Brown et al. 1991; Seidman et al. 1997). The learning deficit in the present experiment was not caused by hyperactivity, because these foodrestricted transgenic mice were not hyperactive (Fig. 4). In addition, the learning deficit cannot be attributed to hypoactivity in the male transgenic mice because only the male mice were hypoactive but both male and female transgenic mice showed a learning impairment. The learning impairment is apparently not attributable to grossly impaired attention, as all indices of attentional function on reaction-time and go/no-go tasks were normal (Table 1). However, it remains possible that the learning impairment may be caused by a mild attentional deficit that adversely affects some components of complex learning tasks but is not detectable by the reaction-time or go/no-go tasks. Alternatively, the learning impairment may reflect an attentional deficit that was evident in the initial exposure to the operant environment, but abated with continued exposure and repeated practice with the lever-press contingencies. The interpretation of a transient deficit is supported by the autoshaping data (Fig. 2), which show an initial delay in acquisition followed by a learning rate equivalent to that of the wild-type controls.

Neither male nor female transgenic mice exhibited behaviors indicating impaired attention or impulsivity, as measured by performance on the simple reaction time and go/no-go tasks. Reaction time, $p$ (hit), and $p$ (FA) were not significantly different between the wild-type and control mice. A factor that must be considered in this analysis is the reinforcer. On unreinforced reaction-time and go/ no-go experiments, ADHD subjects show slower response latencies, fewer hits, and more false alarms (Sergeant and Scholten 1983, 1985; O'Dougherty et al. 1984; Tarnowski et al. 1986; Woodard and Lansdown 1988). However, there is evidence that use of reinforcers may interact with performance on a reaction-time and go/no-go tasks. Iaboni et al. (1995) used a procedure in which ADHD subjects received a nickel for each hit and took away a nickel for each false alarm. Under these conditions ADHD subjects showed identical $p$ (hit) as control subjects, although $p$ (FA) remained significantly higher than controls. In a related experiment, reaction times of ADHD subjects were slower than normal controls under conditions of partial reinforcement, but were not different when $100 \%$ of hits were reinforced (Douglas and Parry 1994). In the animal analog used in the present experiment, the task necessitated the use of reinforcers to train the animals to press the lever. This may have eliminated any differences that may have existed in the absence of reinforcement. Another factor that may have attenuated any differences between transgenics and wild types is food restriction. The phenotypic expression of hyperactivity in male transgenic mice was not seen after 24 $\mathrm{hr}$ of food restriction. It is possible that phenotypic differences in attention or impulsivity were also eliminated with the introduction of food restriction. Taken as a whole, the differences between human and animal versions of the attentional tasks, specifically the use of food restriction and reinforcement, as well as extensive practice on the lever-press task, may obscure the ability to observe differences between transgenic and wild-type animals. If this is the case, task specifics may have to

$$
\begin{array}{llllllllllllllll} 
& E & A & R & N & I & N & G & \boldsymbol{Q} \\
\mathbf{2 9 7} & M & E & M & O & R & Y
\end{array}
$$


be modified in order to better evaluate attentional abilities in RTH transgenic mice.

Previous studies in rodents and humans suggest that the learning deficits displayed by RTH transgenic mice are likely to be independent of the attentional deficit. Several studies have reported subnormal intelligence and academic achievement in children with RTH that did not exhibit symptoms of ADHD (Weiss et al. 1994; Stein et al. 1995). Similar to the learning deficits exhibited in both male and female RTH transgenic mice, Stein et al. (1995) reported learning deficits in both boys and girls with RTH and without ADHD. There is also neurobiological evidence to support the role of thyroid hormone in the development of areas of the brain associated with learning. In rats, $\mathrm{T} 3$ receptors increase 40-fold in number from gestational day 19 to postnatal day 10, a period during which many brain areas, including the hippocampus, are still developing (Strait et al. 1990). Gould and Butcher (1989) showed that both hyperthyroidism and hypothyroidism in rat pups reduced significantly the size and number of cholinergic neurons in the nucleus basalis magnocellularis, the cholinergic cell bodies that project to the cortex. Although the neuroanatomical mechanism for abnormalities in human RTH patients is not known, impaired $\mathrm{T} 3$ receptor binding during development could result in abnormalities in axonal routing, neuronal proliferation and migration, and the regulation of genes during critical periods (Hauser et al. 1993). Any of these mechanisms could result in damage to brain structures that are critical for optimal learning. As with all conventional transgenics, the RTH behavioral phenotype may result from disruption of normal brain development or from differences in protein levels during adulthood.

Interestingly, body weights were higher in male RTH transgenics than in male wild-type controls in the present experiment. This is in contrast to a previous report describing reduced body weight in RTH transgenic mice compared to controls (Wong et al. 1997). Although the phenotype of reduced body weight in the transgenic mice is consistent with that of the human condition, there is evidence to suggest that reduced body weight is not related directly to thyroid abnormalities. First, in the human RTH phenotype there is variability with respect to weight, with weight loss being reported in $<30 \%$ of the subjects (Hauser et al. 1993; Brucker-Davis et al. 1995). In addition, Wong et al. (1997)reported that body weights of RTH transgenic mice were not correlated with free or total
T4 levels; T3 and TSH levels were normal in their mice. The weight gain in the present experiment, then, represents an unusual phenotype that may be the result of interactions of the TR $\beta$ transgene with other genes in the specific CD-1 parental breeders used in the present study. Similarly, the differences in baseline activity between the present study and Wong et al. may be related to background genes in the specific parental breeders of the outbred CD-1 strain. Further studies using multiple TR $\beta$ mutations in inbred strains are needed to better understand the contribution of the PV RTH transgene to body weight and exploratory activity, and possible interactions with background genes (Banbury Conference on Genetic Background in Mice 1997; Crawley et al. 1997).

In conclusion, male transgenic mice harboring the human PV mutant TR $\beta$ gene exhibited significant hyperactivity, consistent with human ADHD. Male and female transgenic mice exhibited a moderate learning deficit compared to wild-type controls, again consistent with ADHD. Measures of sustained attention and impulsivity were normal in RTH transgenic mice. These results are intriguing from several perspectives. This is the first report of the use of mice on tasks such as reaction time and go/no-go, and demonstrates that complex leverpress tasks can be used with mice to elucidate subtle behavioral phenotypes in transgenic or knockout mice. Second, the present study shows dramatic interactions between the behavioral phenotype governed by the transgene and imposed conditions such as food restriction. Third, this is the first molecularly defined model of ADHD; although the mechanism is not well understood, the RTH transgenic mouse model provides a useful tool for investigating multiple genes in diverse biochemical pathways relevant to the etiology of ADHD. Finally, these results represent a partial behavioral analog of the human RTH condition, with respect to the functional relations across species as well as the gender-specificity of the hyperactivity in $\mathrm{ADHD}$, and a good starting point from which to explore further the behavioral phenotype of transgenic mice bearing the RTH mutant TR $\beta 1$ receptor.

\section{Acknowledgments}

We are grateful for the expert technical advice provided by Jill McGaughy, and assistance with behavioral testing provided by Elena McComas and Simrun Kalra.

The publication costs of this article were defrayed in

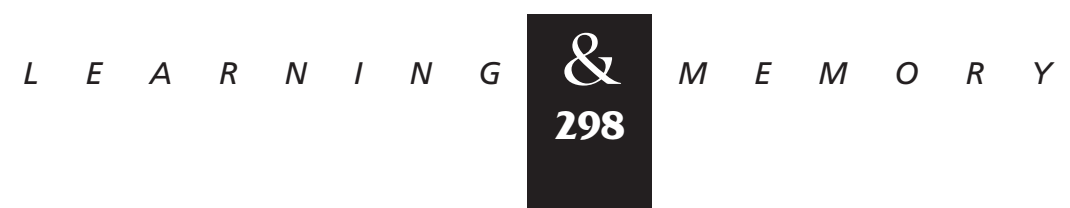


part by payment of page charges. This article must therefore be hereby marked "advertisement" in accordance with 18 USC section 1734 solely to indicate this fact.

\section{References}

Auchus, R.J. and S.A.W. Fuqua. 1994. Clinical syndromes of hormone receptor mutations: Hormone resistance and independence. Semin. Cell. Biol. 5: 127-136.

Banbury Conference on Genetic Background in Mice 1997. Mutant mice and neuroscience: Recommendations concerning genetic background. Banbury Conference on genetic background in mice. Neuron 19: 755-759.

Barkley, R.A. 1981. Hyperactive children: A handbook for diagnosis and treatment. Guilford Press, New York, NY.

Barkley, R.A. 1982. Guidelines for defining hyperactivity in children. In Advances in clinical child psychology (ed. B.B. Lahey and A.E. Kazdin), Vol. 5, pp. 153-180. Plenum Press, New York, NY.

Barkley, R.A. 1997. Behavioral inhibition, sustained attention, and executive functions: Constructing a unifying theory of ADHD. Psychol. Bull. 121: 65-94.

Barkley, R.A., G. Grodzinsky, and G.J. DuPaul. 1992. Frontal lobe functions in attention deficit disorder with and without hyperactivity: A review and research report. J. Abnorm. Child Psychol. 20: 163-188.

Berry, C.A., S.E. Shaywitz, and B.A. Shaywitz. 1985. Girls with attention deficit disorder: A silent minority? A report on behavioral and cognitive characteristics. Pediatrics

76: 801-809.

Breen, M.J. 1989. Cognitive and behavioral differences in ADHD boys and girls. J. Child Psychol. Psychiatry 30: 711-716.

Brown, R.T., A. Madan-Swain, and K. Baldwin. 1991. Gender differences in a clinic-referred sample of attention-deficit-disordered children. Child Psychiatry Hum. Dev. 22: 111-128.

Brucker-Davis, F., M.C. Skarulis, M.B. Grace, J. Benichou, P. Hauser, E. Wiggs, and B.D. Weintraub. 1995. Genetic and clinical features of 42 kindreds with resistance to thyroid hormone. Ann. Intern. Med. 123: 572-583.

Casey, B.J., F.X. Castellanos, J.N. Giedd, W.L. Marsh, S.D. Hamburger, A.B. Schubert, Y.C. Vauss, A.C. Vaituzis, D.P. Dickstein, S.E. Sarfatti, and J.L. Rapoport. 1997. Implication of right frontostriatal circuitry in response inhibition and attention-deficit/hyperactivity disorder. J. Am. Acad. Child Adolesc. Psychiatry 36: 374-383.

Challet, E., Y. Le Maho, P. Pevet, P. Nobelis, and A. Malan. 1996. Ventromedial hypothalamic lesions prevent the fasting-induced changes in day-night pattern of locomotor activity. Behav. Brain Res. 77: 155-163.
Cheng, S.-Y. 1995. New insights into the structure and function of the thyroid hormone receptor. J. Biomed. Sci. 2: 77-89.

Crawley, J.N., J.K. Belknap, A. Collins, J.C. Crabbe, W. Frankel, N. Henderson, R.J. Hitzemann, S.C. Maxson, L.L. Miner, A.J. Silva, J.M. Wehner, A. Wynshaw-Boris, and R. Paylor. 1997. Behavioral phenotypes of inbred mouse strains: Implications and recommendations for molecular studies. Psychopharmacology 132: 107-124.

Douglas, V.I. and P.A. Parry. 1994. Effects of reward and nonreward on frustration and attention in attention deficit disorder. J. Abnorm. Child Psychol. 22: 281-302.

Dudchenko, P., B. Paul, and M. Sarter. 1992. Dissociation between the effects of benzodiazepine receptor agonists on behavioral vigilance and responsivity. Psychopharmacology 109: 203-211.

Forrest, D., E. Hanebuth, R.J. Smeyn, N. Everds, C.L. Stewart, J.M. Wehner, and T. Curran. 1996. Recessive resistance to thyroid hormone in mice lacking thyroid hormone receptor- $\beta$ : Evidence for tissue-specific modulation of receptor function. EMBO J. 15: 3006-3015.

Gould, E. and L.L. Butcher. 1989. Developing cholinergic basal forebrain neurons are sensitive to thyroid hormone. J. Neurosci. 9: 3347-3358.

Grier, J.B. 1971. Nonparametric indexes for sensitivity and bias: Computing formulas. Psychol. Bull. 75: 424-429.

Hauser, P., A.J. Zametkin, P. Martinez, B. Vitiello, J.A. Matochik, A.J. Mixson, and B.D. Weintraub. 1993. Attention deficit-hyperactivity disorder in people with generalized resistance to thyroid hormone. N. Engl. J. Med. 328: $997-1001$.

Hess, E.J., H.A. Jinnah, C.A. Kozak, and M.C. Wilson. 1992. Spontaneous locomotor hyperactivity in a mouse mutant with a deletion including the Snap gene on chromosome 2. J. Neurosci. 12: 2865-2874.

Hogan, B. and E. Lacy. 1986. Manipulating the mouse embryo. Cold Spring Harbor Laboratory, Cold Spring Harbor, NY.

Horn, W.F., A.E. Wagner, and N. lalongo. 1989. Sex differences in school-aged children with pervasive attention deficit hyperactivity disorder. J. Abnorm. Child Psychol. 17: 109-125.

Iaboni, F., V.I. Douglas, and A.G. Baker. 1995. Effects of reward and response cost on inhibition in ADHD children. J. Abnorm. Psychol. 104: 232-240.

Jameson, J.L. 1994. Mechanisms by which thyroid hormone receptor mutations cause clinical syndromes of resistance to thyroid hormone. Thyroid 4: 485-492.

Knardahl, S. and T. Sagvolden. 1979. Open-field behavior of spontaneously hypertensive rats. Behav. Neural Biol. 27: 187-200.

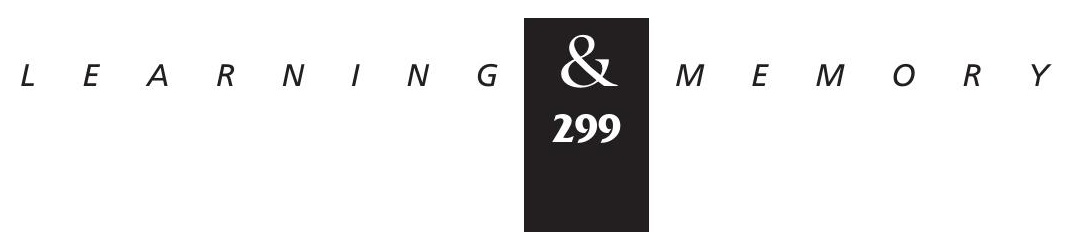




\section{McDonald et al.}

Luthman, J., A. Fredriksson, T. Lewander, G. Jonsson, and T. Archer. 1989. Effects of d-amphetamine and methylphenidate on hyperactivity produced by neonatal 6-hydroxydopamine treatment. Psychopharmacology 99: 550-557.

Matochik, J.A., A.J. Zametkin, R.M. Cohen, P. Hauser, and B.D. Weintraub. 1996. Abnormalities in sustained attention and anterior cingulate metabolism in subjects with resistance to thyroid hormone. Brain Res. 723: 23-28.

McGaughy, J. and M. Sarter. 1995a. Behavioral vigilance in rats: Task validation and effects of age amphetamine and benzodiazepine receptor ligands. Psychopharmacology 117: 340-357.

McGaughy, J. and M. Sarter. 1995b. Effects of chlordiazepoxide and scopolamine but not aging on the detection and identification of conditional visual stimuli. J. Gerontol. A Biol. Sci. Med. Sci. 50: B90-B96.

McGaughy, J., T. Kaiser, and M. Sarter. 1996. Behavioral vigilance following infusions of $192 \mathrm{lgG}$-saporin into the basal forebrain: Selectivity of the behavioral impairment and relation to cortical AChE-positive fiber density. Behav. Neurosci. 110: 247-265.

McGaughy, J., M. Sandstrom, S. Ruland, J.P. Bruno, and M. Sarter. 1997. Lack of effects of lesions of the dorsal noradrenergic bundle on behavioral vigilance. Behav. Neurosci. 111: 646-652.

Meier, C.A., B.M. Dickstein, K. Ashizawa, J.H. McClaskey, P. Muchmore, S.C. Ransom, J.B. Menke, E.H. Hao, S.J. Usala, B.B. Bercu, S.-Y. Cheng, and B.D. Weintraub. 1992. Variable transcriptional activity and ligand binding of mutant beta-1 3,5,3'-triiodothyronine receptors from four families with generalized resistance to thyroid hormone. Mol. Endocrinol. 6: $248-258$.

Mixson, A.J., R. Parilla, S.C. Ransom, E.A. Wiggs, J.H. McClaskey, P. Hauser, and B.D. Weintraub BD. 1992. Correlations of language abnormalities with localization of mutations in the beta-thyroid hormone receptor in 13 kindreds with generalized resistance to thyroid hormone: Identification of four new mutations. J. Clin. Endocrinol. Metab. 75: 1039-1045.

Muir, J.L., T.W. Robbins, and B.J. Everitt. 1992. Disruptive effects of muscimol infused into the basal forebrain on conditional discrimination and visual attention: Differential interactions with cholinergic mechanisms.

Psychopharmacology 107: 541-550.

O'Dougherty, M., K.H. Nuechterlein, and B. Drew. 1984. Hyperactive and hypoxic children: Signal detection, sustained attention and behavior. J. Abnorm. Psychol. 93: 178-191.

Pang, K., F. Merkel, H. Egeth, and D.S. Olton. 1992. Expectancy and stimulus frequency: A comparative analysis in rats and humans. Percept. Psychophys. 51: 607-615.
Pang, K., M.J. Williams, H. Egeth, and D.S. Olton. 1993. Nucleus basalis magnocellularis and attention: Effects of muscimol infusions. Behav. Neurosci. 107: 1031-1038.

Parilla, R., A.J. Mixson, J.A. McPherson, J.H. McClaskey, and B.D. Weintraub. 1991. Characterization of seven novel mutations of the $C$-erbA $\beta$ gene in unrelated kindreds with generalized thyroid hormone resistance: Evidence for two "hot spot" regions of the ligand binding domain. J. Clin. Invest. 88: 2123-2130.

Refetoff, S. 1982. Syndromes of thyroid hormone resistance. Am. J. Physiol. 243: E88-E98.

Refetoff, S., L.T. DeWind, and L.J. DeGroot. 1967. Familial syndrome combining deaf-mutism stippled epiphyses goiter and abnormally high PBI: Possible target organ refractoriness to thyroid hormone. J. Clin. Endocrinol. Metab. 27: 279-294.

Refetoff, S., A. Salazar, T.J. Smith, and N.H. Scherberg. 1983. The consequences of inappropriate treatment because of failure to recognize the syndrome of pituitary and peripheral tissue resistance to thyroid hormone. Metabolism 32: $822-834$.

Refetoff, S., R.E. Weiss, and S.J. Usala. 1993. The syndromes of resistance to thyroid hormone. Endocr. Rev. 14: 348-399.

Sagvolden, T., M.B. Pettersen, and M.C. Larsen. 1993. Spontaneously hypertensive rats (SHR) as a putative animal model of childhood hyperkinesis: SHR behavior compared to four other rat strains. Physiol. Behav. 54: 1047-1055.

Seidman, L.J., J. Biederman, S.V. Faraone, and W. Weber. 1997. A pilot study of neuropsychological function in girls with ADHD. J. Am. Acad. Child Adolesc. Psychiatr. 36: 366-373.

Sergeant, J.A. and C.A. Scholten. 1983. Encoding search and decision in hyperactivity. J. Child Psychol. Psychiatr. 24: 49-60.

Sergeant, J.A. and C.A. Scholten. 1985. On data limitations in hyperactivity. J. Child Psychol. Psychiatr. 26: 111-124.

Steckler, T. and A. Sahgal. 1995. Psychopharmacological studies in rats responding at touch-sensitive devices. Psychopharmacology 118: 226-229.

Stein, M.A., R.E. Weiss, and S. Refetoff. 1995. Neurocognitive characteristics of individuals with resistance to thyroid hormone: Comparisons with individuals with attention-deficit hyperactivity disorder. J. Dev. Behav. Pediatr. 16: $406-411$.

Strait, K.A., H.A. Schwatrz, A. Perez-Castillo, and J.H. Oppenheimer. 1990. Relationship of c-erbA mRNA content to tissue triiodothyronine nuclear binding capacity and function in developing and adult rats. J. Biol. Chem. 265: 10514-10521.

Takeda, K., A. Sakurai, L.J. DeGroot, and S. Refetoff. 1992. Recessive inheritance of thyroid hormone resistance caused by complete deletion of the protein-coding region of the

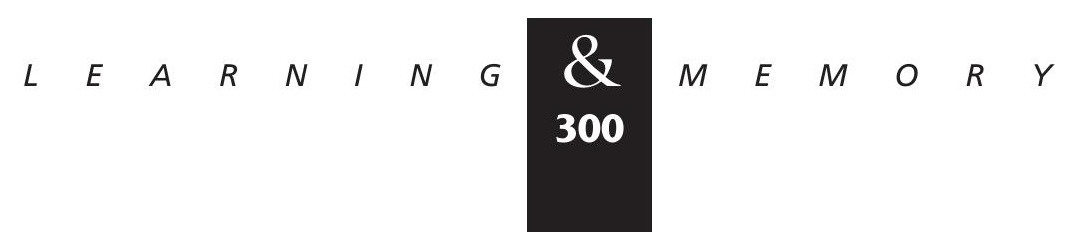


thyroid hormone receptor- $\beta$ gene. J. Clin. Endocrinol. Metab. 74: 49-55.

Tarnowski, K.J., R.J. Prinz, and S.M. Nay. 1986. Comparative analysis of attentional deficits in hyperactive and learning-disabled children. J. Abnorm. Child Psychol. 95: $341-345$.

Trites, R.L., E. Dugas, G. Lynch, and B.H. Ferguson. 1979. Prevalence of hyperactivity. J. Paediatr Psychol. 4: 179-188.

Usala, S.J. 1994. Resistance to thyroid hormone in children. Curr. Opin. Pediatr. 6: 468-475.

Usala, S.J., J.B. Menke, T.L. Watson, F.E. Wondisford, B.D. Weintraub, J. Berard, W.E.C. Bradley, S. Ono, O.T. Meuller, and B.B. Bercu. 1991. A homozygous deletion in the $\mathrm{C}$-erbA $\beta$ thyroid hormone receptor gene in a patient with generalized thyroid hormone resistance: Isolation and characterization of the mutant receptor. Mol. Endocrinol. 5: 327-335.

Weintraub, B.D., M.C. Gershengorn, I.A. Kourides, and H. Fein. 1981. Inappropriate secretion of thyroid stimulating hormone. Ann. Intern. Med. 95:339-351.

Weiss, R.E., M.A. Stein, S.C. Duck, B. Chyna, W. Phillips, T. O'Brien, L. Gutermuth, and S. Refetoff. 1994. Low intelligence but not attention deficit hyperactivity disorder is associated with resistance to thyroid hormone caused by mutation $\mathrm{R} 316 \mathrm{H}$ in the thyroid hormone receptor beta gene. J. Clin. Endocrinol. Metab. 78: 1525-1528.

Wong, R., V.V. Vasilyev, Y.T. Ting, D.I. Kutler, M. Willingham, B.D. Weintraub, and S.-Y. Cheng. 1997. Transgenic mice bearing a human mutant thyroid hormone $\beta 1$ receptor manifest thyroid function anomalies weight reduction and hyperactivity. Mol. Med. 3: 303-314.

Woodard, M. and R. Lansdown. 1988. Language and communication. In Problems of preschool children (ed. N. Richman and R. Lansdown), pp. 55-74. John Wiley Sons, Chichester, UK.

Zahn T.P., J.L. Rapoport, and C.L. Thompson. 1980. Autonomic and behavioral effects of dextroamphetamine and placebo in normal and hyperactive prepubertal boys. J. Abnorm. Child Psychol. 8: 145-160.

Zahn, T.P., M.J. Kruesi, and J.L. Rapoport. 1991. Reaction time indices of attention deficits in boys with disruptive behavior disorders. J. Abnorm. Child Psychol. 19: 233-252.

Zametkin A.J. and J.L. Rapoport. 1987. Neurobiology of attention deficit disorder with hyperactivity: Where have we come in 50 years? J. Am. Acad. Child Adolesc. Psychiatry 26: $676-686$.

Received February 6, 1998; accepted in revised form July 17, 1998.

$$
\begin{array}{llllllllllllllll}
\hline & E & A & R & N & I & N & G & \mathbf{Z} & M & E & M & 0 & R & Y
\end{array}
$$




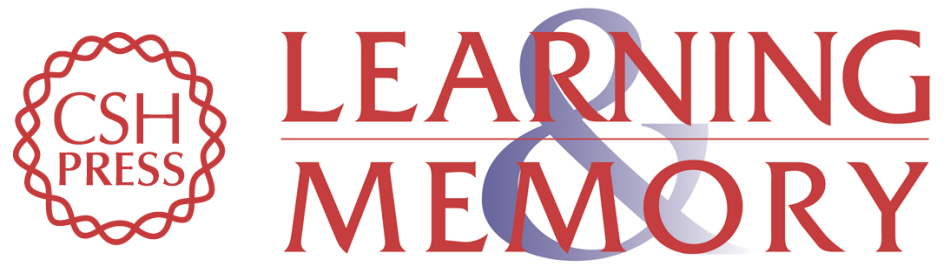

\section{Hyperactivity and Learning Deficits in Transgenic Mice Bearing a Human Mutant Thyroid Hormone $\beta 1$ Receptor Gene}

Michael P. McDonald, Rosemary Wong, Gregory Goldstein, et al.

Learn. Mem. 1998, 5:

Access the most recent version at doi:10.1101//m.5.4.289

References This article cites 55 articles, 3 of which can be accessed free at: http://learnmem.cshlp.org/content/5/4/289.full.html\#ref-list-1

License

Email Alerting Receive free email alerts when new articles cite this article - sign up in the box at the Service top right corner of the article or click here. 